\title{
Validity of upfront surgery for patients with unsuspected lymph node metastasis in esophageal cancer: a propensity scoring matching study
}

\author{
Jae Kil Park', Jae Jun Kim², Seok Whan Moon ${ }^{2}$ and Deog Gon Cho ${ }^{3}$
}

\begin{abstract}
Background: Although neoadjuvant therapy followed by esophagectomy is well-established as being superior to upfront esophagectomy when locoregional lymph node (LN) metastasis is present in esophageal cancer, upfront esophagectomy without neoadjuvant therapy may be performed in patients with LN metastasis due to unreliable preoperative evaluations. However, outcomes in this setting remain unclear. The purpose of the present study was to clarify whether upfront esophagectomy without neoadjuvant therapy in patients with unsuspected lymph node metastasis in esophageal cancer is appropriate.
\end{abstract}

Methods: We included 215 squamous cell esophageal cancer patients who met the study criteria. Inclusion criteria included complete (RO) and curative surgery cases, intra-thoracic esophageal cancer, preoperative biopsy-proven squamous cell carcinoma, and cases without LN metastasis ( $\mathrm{WL}, \mathrm{CNO}$ and $\mathrm{pNO}$ ) or with unsuspected LN metastasis ( $U \mathrm{~L}, \mathrm{CNO}$ and pN1). Exclusion criteria were palliation or salvage cases, other uncured previous or current primary cancers, complete remission cases, and operative mortalities (defined as patients who died during hospitalization or within one month after surgery). We compared 5-year disease- free survival (DFS) between WL and UL. In addition, we investigated the influence of neoadjuvant therapy in UL. To overcome heterogeneity in baseline characteristics between the groups, a propensity matched-analysis based on propensity scores was then carried out to create a cohort of WL with clinical characteristics similar to those in UL.

Results: The incidence of UL among preoperative NO patients was $25.6 \%$ and the incidence of UL cases who did not receive neoadjuvant therapy was $47.2 \%$. All subjects were stratified into either WL (160 patients) or UL (55 patients). Twenty nine of 55 patients in UL received neoadjuvant therapy before esophagectomy and all patients with $L N$ metastasis received adjuvant therapy after esophagectomy. There was no significant difference in DFS between WL and UL $(p=0.242)$. Furthermore, there were no significant differences in DFS between cases that received and did not receive neoadjuvant therapy $(p=0.769)$.

Conclusions: Upfront surgery without neoadjuvant therapy in UL is appropriate for patients who can tolerate adjuvant therapy.

Keywords: Esophageal cancer, Lymph node metastasis, Neoadjuvant therapy

\footnotetext{
* Correspondence: medkjj@hanmail.net

2Department of Thoracic and Cardiovascular Surgery, Uijeongbu St. Mary's

Hospital, The Catholic University of Korea College of Medicine, 271 Cheonbo

Street, Uijeongbu City, Gyeonggi-do 480-717, South Korea

Full list of author information is available at the end of the article
}

(c) The Author(s). 2018 Open Access This article is distributed under the terms of the Creative Commons Attribution 4.0 International License (http://creativecommons.org/licenses/by/4.0/), which permits unrestricted use, distribution, and reproduction in any medium, provided you give appropriate credit to the original author(s) and the source, provide a link to the Creative Commons license, and indicate if changes were made. The Creative Commons Public Domain Dedication waiver (http://creativecommons.org/publicdomain/zero/1.0/) applies to the data made available in this article, unless otherwise stated. 


\section{Background}

The basic treatment strategy for esophageal cancer depends on the cancer stage [1-5]. Neoadjuvant therapy is usually recommended for patients with lymph node (LN) metastases in esophageal cancer [2, 4, 6]. In esophageal cancer, positron emission tomography computed tomography (PET-CT) is essential to the evaluation of the cancer stage, especially with respect to distant or locoregional LN metastases [7-10]. A lesion is usually regarded to be malignant or metastatic when the maximum standardized uptake value is $\geq 2.5$ and the size is $\geq 1 \mathrm{~cm}$ on PET-CT and endoscopic ultrasound [11, 12]. However, discrepancies between the preoperative evaluations and the pathologic findings are not uncommon, especially in locoregional LN [12, 13]. Because thoracic surgeons do not usually perform an invasive evaluation for locoregional LN when the LN is negative on PET-CT and endoscopic ultrasound, the preoperative evaluation might provide inaccurate information and influence the management plan and prognosis. Although neoadjuvant therapy followed by esophagectomy is well-established as being superior to upfront esophagectomy when LN metastasis is present in esophageal cancer, there are uncertainties regarding upfront esophagectomy without neoadjuvant therapy for clinically unsuspected LN metastasis cases [7, 11, 14, 15]. In reality, due to unreliable preoperative clinical evaluation, upfront esophagectomy without neoadjuvant therapy may be performed in a patient with LN metastasis. However, outcomes in this setting remain unclear [16]. In other words, whether prognosis varies between patients without LN metastasis (WL: cNO and pNO) and those with unsuspected LN metastasis (UL: cN0 and pN1) needs to be elucidated. Additionally, although complete resection is an important prognostic factor for esophageal cancer, it remains unclear whether neoadjuvant therapy is beneficial for UL. The purpose of the present study was to clarify whether upfront esophagectomy without neoadjuvant therapy is appropriate in UL.

\section{Methods}

\section{Study subjects and methods}

We retrospectively compiled and analyzed data from patients who had undergone curative and complete surgery for intra-thoracic esophageal cancers at a single tertiary Korean hospital from January 2009 to December 2015. Inclusion criteria were complete (R0) and curative surgery cases, intra-thoracic esophageal cancer, preoperative biopsy-proven squamous cell carcinoma, and cases with WL or UL. Exclusion criteria were palliation or salvage cases, other uncured previous or current primary cancers, complete remission cases after neoadjuvant therapy, and operative mortalities (defined as patients who died during hospitalization or within one month after surgery). The preoperative evaluations included esophagogastroduodenoscopy, esophagography, chest CT, abdominal CT, PET- CT, endoscopic ultrasound, and bone scan. In the present study, lesions were regarded as malignant or metastatic when the maximum standardized uptake value was $\geq 2.5$ and the size was $\geq 1 \mathrm{~cm}$ on PET- CT and endoscopic ultrasound. Neoadjuvant and adjuvant therapies were usually performed following the National Comprehensive Cancer Network guidelines or the recommendations from a multidisciplinary team who assessed cancer status and each patient's condition [4, 17]. Neoadjuvant therapy usually consisted of two cycles of cisplatin and 5-fluorouracil, plus 25 fractions of radiation therapy (over five weeks) to a total of 41-45 Gray. Re-evaluation by PET- CT was performed four weeks after completion of neoadjuvant therapy, and further management was determined. In those cases receiving neoadjuvant therapy, surgery was usually preformed five or six weeks after neoadjuvant therapy completion. In the present study, preoperative stage in neoadjuvant cases was defined as clinical stage by PET-CT reevaluation after completion of neoadjuvant therapy and before surgery. Surgeries were performed by two thoracic surgeons using Ivor Lewis or McKeown procedure depending on cancer status. Patients were usually followed at 3-month intervals for one year after treatment completion, including adjuvant therapy, and then at 6-month intervals. Recurrence or metastasis was diagnosed based on imaging findings including PET-CT, brain MRI, and bone scan, or pathological confirmation when clinically feasible. Cancer stage was determined with regard to the seventh American Joint Committee on Cancer staging system.

UL status is defined as having pathologic evidence of metastatic esophageal cancer in LN after esophagectomy in preoperative cases without $\mathrm{LN}$ metastasis (i.e. cN0 on the preoperative evaluations, but $\mathrm{pN} 1$ on the postoperative pathologic findings). Since most patients were in an early cancer stage, the sample size was small, and various factors after recurrence can influence overall survival, we carried out a 5 -year disease-free survival (DFS) study instead of an overall survival study to clarify whether upfront esophagectomy without neoadjuvant therapy in UL is appropriate. To clarify the validity of upfront esophagectomy in UL, we compared DFS between WL and UL. In addition, we investigated the benefit of neoadjuvant therapy in UL.

\section{Statistical considerations and study approval}

The Student's T test was used to compare the groups with continuous variables. The Chi-squared test or the Fisher's exact test was used to evaluate the associations between the groups with categorical variables as appropriate. Disease-free intervals were measured from time of surgery to time of recurrence or last follow-up. DFS between WL and UL was compared using the Kaplan-Meier method 
Table 1 .Overall clinic-pathologic characteristics for the study subjects.

\begin{tabular}{|c|c|c|c|c|}
\hline \multicolumn{2}{|l|}{ Variables } & \multirow{2}{*}{$\begin{array}{l}\mathrm{WL} \\
(N=160) \\
63.5( \pm 9.1)\end{array}$} & \multirow{2}{*}{$\begin{array}{l}\text { UL } \\
(N=55) \\
60.7( \pm 6.7)\end{array}$} & \multirow{2}{*}{$\begin{array}{r}P \text {-value } \\
0.014\end{array}$} \\
\hline Age (year) & & & & \\
\hline \multirow[t]{2}{*}{ Sex } & Male & 144 & 55 & 0.014 \\
\hline & Female & 16 & 0 & \\
\hline \multirow[t]{3}{*}{ Preoperative T stage } & 1 & 95 & 23 & 0.001 \\
\hline & 2 & 50 & 11 & \\
\hline & 3 & 15 & 21 & \\
\hline \multirow[t]{4}{*}{ Postoperative T stage } & $1 a$ & 48 & 3 & $<0.001$ \\
\hline & $1 b$ & 68 & 13 & \\
\hline & 2 & 19 & 21 & \\
\hline & 3 & 25 & 18 & \\
\hline \multirow[t]{3}{*}{ Location of cancer } & Upper thoracic & 22 & 3 & 0.254 \\
\hline & Middle thoracic & 78 & 31 & \\
\hline & Lower thoracic & 60 & 21 & \\
\hline \multirow[t]{2}{*}{ Method of surgery } & Ivor Lewis & 148 & 45 & 0.080 \\
\hline & McKeown & 114 & 10 & \\
\hline \multirow[t]{3}{*}{ Differentiation } & Well & 24 & 3 & 0.351 \\
\hline & Moderate & 109 & 52 & \\
\hline & Poor & 27 & 0 & \\
\hline \multirow[t]{2}{*}{ Neoadjuvant therapy } & No & 136 & 26 & $<0.001$ \\
\hline & Yes & 24 & 29 & \\
\hline
\end{tabular}

with log-rank test. The influence of neoadjuvant therapy on prognosis in UL was also evaluated using the Kaplan-Meier method with log-rank test. To overcome heterogeneity in baseline characteristics between the groups, a matched-analysis based on propensity scores was then carried out to create a cohort of WL patients with clinical characteristics similar to those in the UL. Covariates included age, sex, pathological T stage, method of esophagectomy, and receipt of neoadjuvant therapy. All statistical analyses were performed using the Statistical Package of Social Sciences version 22.0 (Chicago, IL, USA). A p- value less than 0.05 (two- sided) was regarded as statistically significant. This study was approved by the
Institutional Review Board of Seoul St. Mary's Hospital (IRB approval number: KC17RESI0293).

\section{Results}

Study subjects

The incidence of UL among preoperative N0 patients was $25.6 \%$ and the incidence of UL cases who did not receive neoadjuvant therapy was $47.2 \%$. We included 215 patients (male 199, female 19; mean age 62.8 \pm 8.6 years) who met the study criteria. All subjects were stratified into either WL (160 patients) or UL (55 patients). Twenty nine of 55 patients in UL received neoadjuvant therapy before esophagectomy and all patients with LN metastasis received adjuvant therapy after esophagectomy. All cancer histologies confirmed squamous cell carcinomas. Tumors were located in the upper thoracic esophagus ( 25 cases), middle thoracic esophagus (109 cases), and lower thoracic esophagus (81 cases). The mean tumor length and size were $3.0( \pm 2.2) \mathrm{cm}$ and $8.3( \pm 13.8) \mathrm{cm}^{2}$, respectively. The mean number of LN dissected was $24.3( \pm 11.0)$. The mean observation period was $29.3( \pm 20.3)$ months. Recurrence was found in 46 patients during the observation period. The overall clinico-pathologic characteristics of the study subjects are summarized in Table 1.

\section{Prognosis between WL and UL}

There were $160 \mathrm{WL}$ and $55 \mathrm{UL}$ patients. Fifty three patients received neoadjuvant therapy (24 in WL and 29 in UL). We analyzed DFS between WL and UL after propensity score matching to overcome heterogeneity between WL and UL. Covariates included age, sex, neoadjuvant therapy, method of surgery, and pathological $\mathrm{T}$ stage (Table 2).There were $55 \mathrm{WL}$ cases and 55 UL cases after propensity score matching. There was no significant difference in DFS between WL and UL (Fig. 1. $p=0.242$ ).

\section{Influence of neoadjuvant therapy in UL}

Twenty nine of 55 patients in UL received neoadjuvant therapy and all patients in UL received adjuvant therapy after surgery. To clarify the influence of neoadjuvant therapy in UL, we compared DFS between UL cases that received and did not receive neoadjuvant therapy after propensity score matching to overcome heterogeneity

Table 2 Propensity score matching description

\begin{tabular}{|c|c|c|c|c|c|c|c|c|}
\hline \multirow[t]{2}{*}{ Covariates } & \multicolumn{4}{|c|}{ Total Population } & \multicolumn{4}{|c|}{ Propensity-matched Population } \\
\hline & $\begin{array}{l}\text { WL } \\
(n=160)\end{array}$ & $\begin{array}{l}U L \\
(n=55)\end{array}$ & $p$-value & $\begin{array}{l}\text { standardized } \\
\text { difference }\end{array}$ & $\begin{array}{l}\mathrm{WL} \\
(n=55)\end{array}$ & $\begin{array}{l}\text { UL } \\
(n=55)\end{array}$ & $p$-value & $\begin{array}{l}\text { standardized } \\
\text { difference }\end{array}$ \\
\hline Age & $63.5 \pm 9.1$ & $60.7 \pm 6.7$ & 0.014 & -0.430 & $61.0 \pm 9.4$ & $60.7 \pm 6.7$ & 0.842 & -0.046 \\
\hline Sex (Male) & $144(90 \%)$ & 55 (100\%) & 0.014 & $\mathrm{~N} / \mathrm{A}$ & $55(100 \%)$ & $55(100 \%)$ & $\mathrm{N} / \mathrm{A}$ & $\mathrm{N} / \mathrm{A}$ \\
\hline NT & $24(15 \%)$ & $29(52.7 \%)$ & $<0.001$ & 0.749 & $21(38.2 \%)$ & $29(52.7 \%)$ & 0.180 & 0.289 \\
\hline Ivro Lewis & 146 & 45 & 0.080 & 0.242 & 42 & 45 & 0.640 & -0.140 \\
\hline pT Stage & $2.1 \pm 1.0$ & $3.0 \pm 0.9$ & $<0.001$ & 0.953 & $2.6 \pm 1.1$ & $3.0 \pm 0.9$ & 0.132 & 0.448 \\
\hline
\end{tabular}




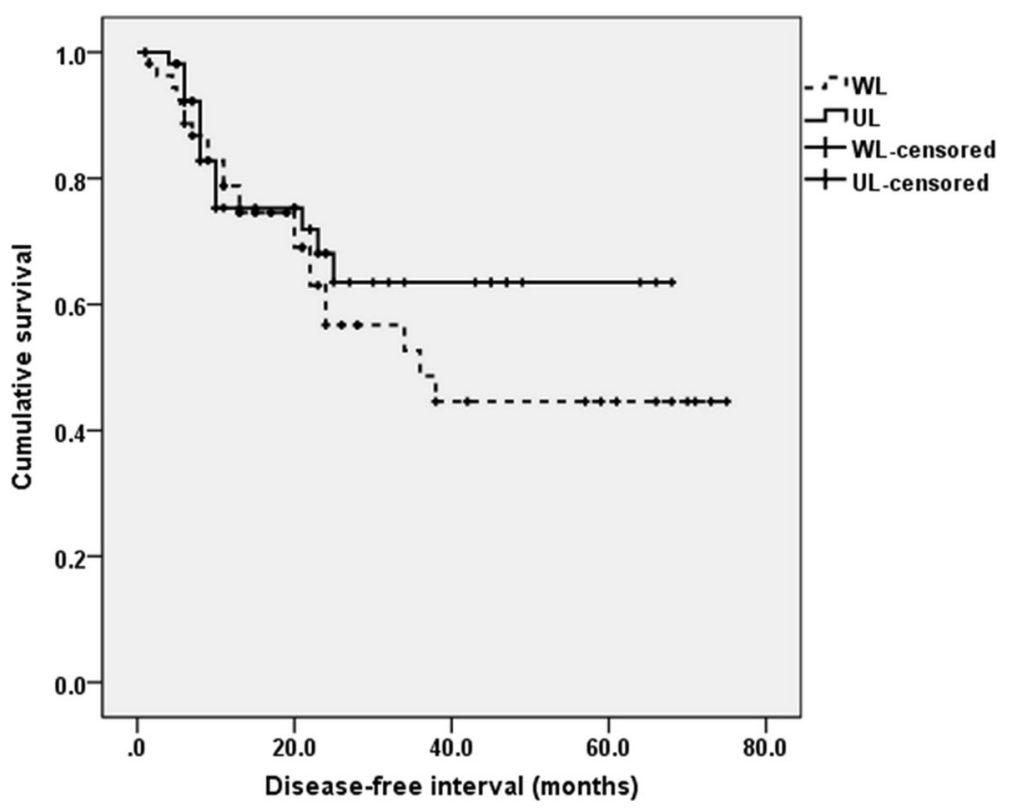

Fig. 1 Prognosis between patients without lymph node metastasis and those with unsuspected lymph node metastasis. There was no significant difference in 5-year disease-free survival between patients without lymph node metastasis $(W L)$ and those with unsuspected lymph node metastasis (UL) after propensity score matching $(p=0.345)$

between the two groups. Covariates included age, method of surgery, and pathological $\mathrm{T}$ stage (Table 3). There were 26 cases each that receive and did not receive neoadjuvant therapy, respectively, after propensity score matching. There was no significant difference in DFS between cases that received or did not receive neoadjuvant therapy (Fig. 2, $p=0.769$ ).

\section{Discussion}

Because clinical diagnosis of LN metastasis in esophageal squamous cell carcinoma is not exact and it is well known that LN metastasis is not often detected in small-sized lymph node (less than $10 \mathrm{~mm}$ ), discrepancies between preoperative staging and pathologic findings are not uncommon, especially in locoregional LN [11]. Thoracic surgeons do not usually perform invasive evaluation for a locoregional LN when the LN is negative on PET-CT and upfront surgery without neoadjuvant therapy may be performed on patients with LN metastasis [9]. Although neoadjuvant therapy can increase the rate of postoperative complication or length of hospital stay for patients, neoadjuvant therapy followed by complete esophagectomy (R0) is well-established as being superior to upfront esophagectomy when LN metastasis is present. However, there are uncertainties regarding the management plan and prognosis for UL in esophageal cancer $[2,7,14,15]$. In the present study, to clarify whether upfront surgery without neoadjuvant therapy in UL is appropriate, we compared prognosis between WL and UL and investigated the influence of neoadjuvant therapy in UL.

The present study showed that there was a substantial incidence of UL among preoperative $\mathrm{CNO}$ patients and that a considerable incidence of UL did not receive neoadjuvant therapy. Therefore, the increased use of an invasive evaluation of a locoregional $\mathrm{LN}$ in esophageal cancer might be considered because neoadjuvant therapy is beneficial when LN metastasis is present. However, because there was no significant difference in DFS between WL and UL after upfront esophagectomy (R0) without neoadjuvant therapy, UL does not necessarily

Table 3 Propensity score matching description

\begin{tabular}{|c|c|c|c|c|c|c|c|c|}
\hline \multirow[t]{2}{*}{ Covariates } & \multicolumn{4}{|c|}{ Total Population } & \multicolumn{4}{|c|}{ Propensity-matched Population } \\
\hline & $\begin{array}{l}\text { non- NT } \\
(n=26)\end{array}$ & $\begin{array}{l}\text { NT } \\
(n=29)\end{array}$ & $p$-value & $\begin{array}{l}\text { standardized } \\
\text { difference }\end{array}$ & $\begin{array}{l}\text { non- NT } \\
(\mathrm{n}=26)\end{array}$ & $\begin{array}{l}N T \\
(n=26)\end{array}$ & $p$-value & $\begin{array}{l}\text { standardized } \\
\text { difference }\end{array}$ \\
\hline$\overline{\text { Age }}$ & $62.0 \pm 8.0$ & $59.5 \pm 5.2$ & 0.172 & -0.479 & $62.0 \pm 8.0$ & $59.1 \pm 5.3$ & 0.130 & -0.558 \\
\hline Ivor Lewis & 23 & 22 & 0.303 & 0.289 & 23 & 22 & 0.500 & 0.088 \\
\hline pT Stage & $2.4 \pm 0.9$ & $3.5 \pm 0.5$ & $<0.001$ & 2.084 & $2.4 \pm 0.9$ & $3.5 \pm 0.5$ & $<0.001$ & 2.193 \\
\hline
\end{tabular}




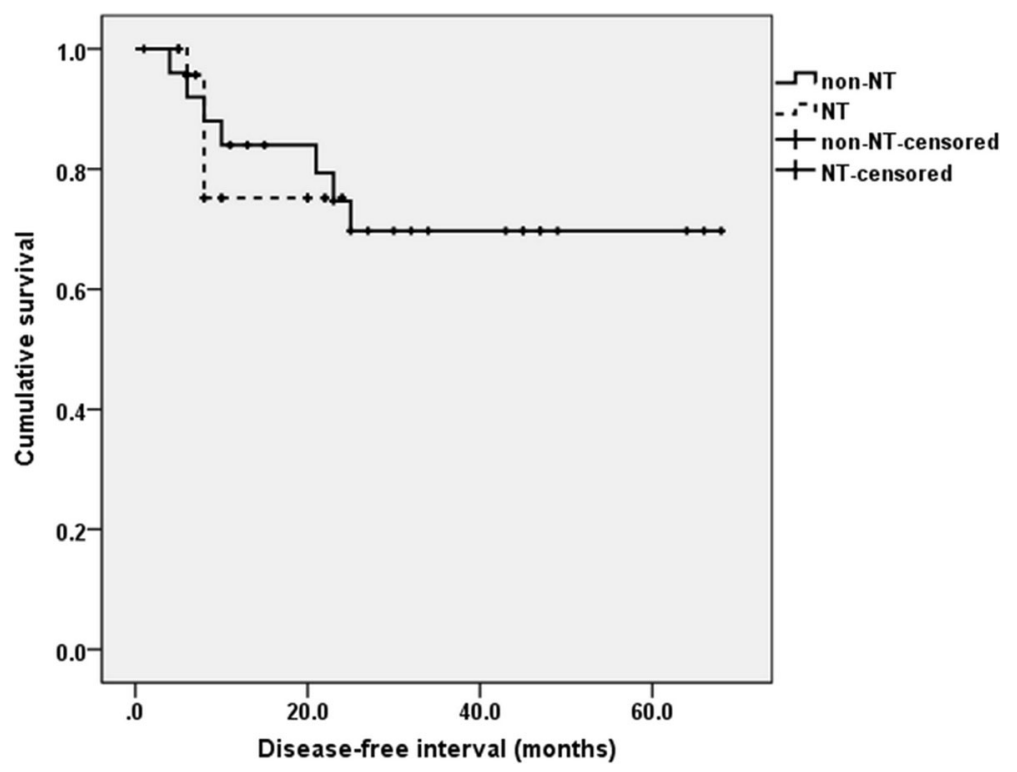

Fig. 2 Influence of neoadjuvant therapy in patients with unsuspected lymph node metastasis. There was no significant difference in 5-year disease-free survival between patients who receive (NT) or did not receive neoadjuvant therapy (non-NT) after propensity score matching $(p=0.769)$

suggest the needs for increased use of invasive evaluation of a locoregional LN when the $\mathrm{LN}$ is determined to be negative by PET- CT.

The findings from the present study also suggested that continuing planned esophagectomy is appropriate if a surgeon faces an unsuspected LN during surgery in patients who will be able to tolerate adjuvant therapy after complete resection. In this study, all patients in UL received adjuvant therapy after surgery. The findings also suggest that surgeons do not need to routinely perform an intraoperative pathologic evaluation of a locoregional LN which was negative in preoperative evaluations to determine whether they continue a planned esophagectomy or not [18].

The present study showed that there was no significant benefit of neoadjuvant therapy in UL, consequently suggesting that upfront surgery without neoadjuvant therapy in UL is appropriate. However, one potential drawback to upfront surgery in UL is the possibility of surgical morbidity influencing the use of adjuvant therapy [19]. When surgeons face an unsuspected LN during surgery, they should consider the patient's likely tolerability of esophagectomy and the subsequent adjuvant therapy $[19,20]$.

There are several limitations in the present study. First, the retrospective nature allows for the possibility of unobserved, and therefore uncontrolled, confounding factors or selection bias. Second, because of the small number of cases, especially in UL, and the possibility that the heterogeneity of the data could have affected the study findings, a propensity score matching method was carried out. Third, the shine-through phenomenon of PET-CT may also have affected preoperative evaluation.

\section{Conclusions}

In the present study, a propensity matched analysis showed that there were no significant differences in DFS between WL and UL after complete resections. In addition, neoadjuvant therapy did not confer a survival benefit in UL when adjuvant therapy was performed after complete resection. Therefore, preoperative invasive evaluation for a locoregional LN is not necessary when the LN is negative on PET-CT and upfront surgery without neoadjuvant therapy in UL is appropriate for patients that will be able to tolerate adjuvant therapy.

\section{Abbreviations}

LN: Lymph node; UL: Patients with unsuspected lymph node metastasis; WL: Patients without lymph node metastasis

\section{Authors' contributions}

(I) Conception and design: Jae Jun Kim; (II) Administrative support: Jae Jun Kim; (III) Provision of study materials or patients: Jae Kil Park; (IV) Collection and assembly of data: Seok Whan Moon; (V) Data analysis and interpretation: Jae Jun Kim and Deog Gon Cho; (VI) Manuscript writing: All authors; (VII) Final approval of manuscript: All authors.

Ethics approval and consent to participate

The present study was approved by the Institutional Review Board of Seoul St. Mary's Hospital (IRB Approval number: KC17RESI0293).

\section{Competing interests}

The authors have no funding, financial relationships or conflicts of interest to disclose. The authors have no competing interests to declare. 


\section{Publisher's Note}

Springer Nature remains neutral with regard to jurisdictional claims in published maps and institutional affiliations.

\section{Author details \\ ${ }^{1}$ Department of Thoracic and Cardiovascular Surgery, Seoul St. Mary's Hospital, The Catholic University of Korea College of Medicine, Seoul, South Korea. ${ }^{2}$ Department of Thoracic and Cardiovascular Surgery, Uijeongbu St. Mary's Hospital, The Catholic University of Korea College of Medicine, 271 Cheonbo Street, Uijeongbu City, Gyeonggi-do 480-717, South Korea. ${ }^{3}$ Department of Thoracic and Cardiovascular Surgery, St. Vincent's Hospital, The Catholic University of Korea College of Medicine, Suwon, South Korea.}

Received: 11 March 2018 Accepted: 1 June 2018

Published online: 07 June 2018

\section{References}

1. Peng J, Wang WP, Dong T, Cai J, Ni PZ, Chen LQ. Refining the nodal staging for esophageal squamous cell carcinoma based on lymph node stations. Ann Thorac Surg. 2016;101(1):280-6.

2. Lordick F, Mariette C, Haustermans K, Obermannova R, Arnold D. Oesophageal cancer: ESMO clinical practice guidelines for diagnosis, treatment and follow-up. Ann Oncol. 2016;27(suppl 5):v50-7.

3. Xu Y, Yu X, Chen $\mathrm{Q}$, Mao W. Neoadjuvant versus adjuvant treatment: which one is better for resectable esophageal squamous cell carcinoma? World J Surg Oncol. 2012;10:173

4. Berry MF. Esophageal cancer: staging system and guidelines for staging and treatment. J Thorac Dis. 2014;6(Suppl 3):S289-97.

5. Rice TW. Esophageal Cancer staging. Korean J Thorac Cardiovasc Surg. 2015; 48(3):157-63.

6. Matsuda S, Tsubosa Y, Sato H, Takebayashi K, Kawamorita K, Mori K, et al. Comparison of neoadjuvant chemotherapy versus upfront surgery with or without chemotherapy for patients with clinical stage III esophageal squamous cell carcinoma. Dis Esophagus. 2017;30(2):1-8.

7. Ozis SE, Soydal C, Akyol C, Can N, Kucuk ON, Yagci C, et al. The role of 18 Ffluorodeoxyglucose positron emission tomography/computed tomography in the primary staging of rectal cancer. World J Surg Oncol. 2014;12:26.

8. Sasaki K, Uchikado Y, Okumura H, Omoto I, Kita Y, Arigami T, et al. Role of 18F-FDG-PET/CT in esophageal squamous cell carcinoma after neoadjuvant Chemoradiotherapy. Anticancer Res. 2017;37(2):859-64

9. Yasuda T, Yano M, Miyata H, Yamasaki M, Higuchi I, Takiguchi S, et al. Systemic control and evaluation of the response to neoadjuvant chemotherapy in resectable thoracic esophageal squamous cell carcinoma with (1)(8)F-fluorodeoxyglucose positron emission tomography-positive lymph nodes. Surg Today. 2015;45(3):335-45

10. Song $\mathrm{H}$, Cho $\mathrm{S}$, Yang $\mathrm{HC}$, Jheon $\mathrm{S}$. The role of maximum standardized uptake value in PET/CT as a prognostic factor in patients with resected esophageal squamous cell carcinoma. Thorac Cardiovasc Surg. 2015:63:335-40.

11. Stiles BM, Mirza F, Coppolino A, Port JL, Lee PC, Paul S, et al. Clinical T2T3NOMO esophageal cancer: the risk of node positive disease. Ann Thorac Surg 2011;92(2):491-6; discussion 6-8.

12. Park JK, Kim JJ, Moon SW. A study about different findings of PET-CT between neoadjuvant and non-neoadjuvant therapy: SUVmax is not a reliable predictor of lymphatic involvement after neoadjuvant therapy for esophageal cancer. J Thorac Dis. 2016:8(5):784-94.

13. Rice TW, Mason DP, Murthy SC, Zuccaro G Jr, Adelstein DJ, Rybicki LA, et al. T2N0M0 esophageal cancer. J Thorac Cardiovasc Surg. 2007;133(2):317-24.

14. Talsma K, Wijnhoven B, van Lanschot J, van Berge Henegouwen M. Impact of neoadjuvant Chemoradiation on lymph node status in esophageal Cancer: post hoc analysis of a randomized controlled trial. Ann Surg. 2015;266(6):e52-3.

15. Shapiro J, van Lanschot JJB, Hulshof MCCM, van Hagen P, van Berge Henegouwen Ml, Wijnhoven BPL, et al. Neoadjuvant chemoradiotherapy plus surgery versus surgery alone for oesophageal or junctional cancer (CROSS): long-term results of a randomised controlled trial. Lancet Oncol. 2015;16(9):1090-8.

16. Okumura H, Uchikado Y, Omoto I, Kita Y, Sasaki K, Arigami T, et al. The usefulness of neoadjuvant chemoradiation therapy for locally advanced esophageal cancer with multiple lymph-node metastases. Ann Surg Oncol. 2014;21(9):2845-9.

17. Klevebro F, Alexandersson von Döbeln $G$, Wang $N$, Johnsen $G$, Jacobsen AB, Friesland $\mathrm{S}$, et al. A randomized clinical trial of neoadjuvant chemotherapy versus neoadjuvant chemoradiotherapy for cancer of the oesophagus or gastro-oesophageal junction. Ann Oncol. 2016;27(4):660-7.

18. Koen Talsma A, Shapiro J, Looman CW, van Hagen P, Steyerberg EW, van der Gaast A, et al. Lymph node retrieval during esophagectomy with and without neoadjuvant chemoradiotherapy: prognostic and therapeutic impact on survival. Ann Surg 2014;260(5):786-792; discussion 92-93.

19. de Heer EC, Hulshoff JB, Klerk D, Burgerhof JGM, de Groot DJA, Plukker JTM, et al. Effect of extending the original eligibility criteria for the CROSS neoadjuvant Chemoradiotherapy on toxicity and survival in esophageal Cancer. Ann Surg Oncol. 2017;24(7):1811-20.

20. De Giacomo T, Trentino P, Venuta F, Tsagkaropoulos S, Berloco PB, Diso D, et al. Surgical treatment of esophageal carcinoma with curative intent: analysis of a single center experience. J Cardiothorac Surg. 2015:8:52.

\section{Ready to submit your research? Choose BMC and benefit from:}

- fast, convenient online submission

- thorough peer review by experienced researchers in your field

- rapid publication on acceptance

- support for research data, including large and complex data types

- gold Open Access which fosters wider collaboration and increased citations

- maximum visibility for your research: over $100 \mathrm{M}$ website views per year

At BMC, research is always in progress.

Learn more biomedcentral.com/submissions 